\title{
Perfil Socioeconômico de Trabalhadores do Segmento de Carvão Vegetal e Percepção da População Local em Curimatá-PI
}

\author{
Ilvan Medeiros Lustosa Júnior ${ }^{1}$, Sidney Araujo Cordeiro², \\ Jailson Silva Machado ${ }^{3}$, Robson José de Oliveira ${ }^{3}$, \\ Rosalvo Maciel Guimarães Neto ${ }^{3}$ \\ ${ }^{1}$ Universidade de Brasília - UNB, Brasília/DF, Brasil \\ ${ }^{2}$ Departamento de Engenharia Florestal, Universidade Federal dos Vales do Jequitinhonha e Mucuri - UFVJM, \\ Diamantina/MG, Brasil \\ ${ }^{3}$ Departamento de Engenharias, Universidade Federal do Piauí - UFPI, Bom Jesus/PI, Brasil
}

\begin{abstract}
RESUMO
O Estado do Piauí vem se destacando na produção de carvão vegetal e a maioria das carvoarias se concentra na região sul do Estado. Estas carvoarias justificam suas atividades com a ideia de promover o incremento econômico na região. Neste sentido, este trabalho tem por objetivo diagnosticar e quantificar os impactos socioeconômicos gerados pela indústria carvoeira para a população do município de Curimatá. Para isto, foi realizada uma coleta de dados em campo, dividida em duas fases: entrevistas em profundidade e aplicação de formulários, com empreendedores, funcionários das carvoarias e população do município. Os dados coletados durante os dois meses de pesquisa em campo foram tabulados em planilha Excel ${ }^{\circ}$, tendo sido gerados os respectivos valores percentuais de forma a facilitar a análise. Os resultados demonstram divergência entre as respostas de funcionários e da população, na medida em que a atividade carvoeira atuante no município de Curimatá parece não satisfazer a população, priorizando apenas poucas pessoas envolvidas diretamente nesta atividade.
\end{abstract}

Palavras-chave: carvão vegetal, estudo socioeconômico, Piauí.

\section{Socioeconomic Profile of Workers from the Charcoal Segment and the Perception of the Local Population in Curimatá, Piaui State}

\begin{abstract}
The state of Piauí has been excelling in the production of charcoal, and most producers are concentrated in the southern region of the state. These producers justify their activities with the idea of promoting economic growth in the region. In this sense, this work aims to diagnose and quantify the economic impacts generated by the coal industry to the population of the municipality of Curimatá. To this end, field data collection was carried out in two phases through in-depth interviews and application of forms to entrepreneurs and employees of the charcoal segment and the municipality's population. The data collected during the two months of field research were tabulated in Excel $^{\circ}$ spreadsheet and their respective percentages were generated in order to facilitate analysis. The results show differences between the responses of employees and population. The charcoal activity in the municipality of Curimatá does not seem to satisfy the population, prioritizing only a few citizens directly involved in this activity.
\end{abstract}

Keywords: charcoal, socioeconomic study, Piauí state. 


\section{INTRODUÇÃO}

A produção de carvão vegetal é uma atividade rentável, que se baseia no processo de carbonização da madeira. Sua história, no Brasil, data de 1921, quando a então recém-criada Empresa BelgoMineira provou a viabilidade de produção em larga escala; entretanto, foi com as políticas de redução da importação de carvão mineral que se obteve grande crescimento. Destaca-se o ano de 1989, cujo pico foi registrado com $40 \%$ da produção de ferro gusa utilizando carvão vegetal, proporção esta que gira em torno de $33 \%$, o que totaliza um consumo de 35.778.000 mdc (metros de carvão) (ABRAF, 2008).

Segundo Moura et al. (2010), a produção do carvão vegetal no Brasil responde por cerca de um terço da produção mundial. Note-se que quase todo esse montante é destinado à siderurgia e muito desta produção ainda é realizada sem as preocupações básicas com o meio ambiente e a segurança do trabalhador. Homma et al. (2006) afirmaram que, para se obter uma tonelada de ferro-gusa, a guseira precisa, em média, de 1,6 tonelada de minério de ferro e $875 \mathrm{~kg}$ de carvão vegetal, além de calcário $(100 \mathrm{~kg})$, manganês $(40 \mathrm{~kg})$ e quartzito $(65 \mathrm{~kg})$.

É neste sentido que Vital \& Pinto (2009) constataram que a produção de carvão vegetal para fabricação de ferro-gusa aumenta diretamente a demanda por madeira. Este fato é comprovado com os dados do IBGE (2012b), demonstrando que, no ano de 2011, o Piauí ficou em quarto lugar no ranking dos produtores de carvão vegetal, sendo responsável por 137,7 mil toneladas do produto.

Segundo a Secretaria do Meio Ambiente e Recursos Hídricos do Piauí - SEMAR (Piauí 2011), o Piauí vem se destacando com esse tipo de atividade, existindo no Estado 77 carvoarias instaladas; entretanto, apenas 55 estão com licenciamento em dia e o restante, com licenças vencidas ou canceladas. $\mathrm{O}$ autor ressalta que a maioria das carvoarias se concentra na região sul do Estado, onde se estima uma produção oficial de 10.000 toneladas por mês, produção destinada ao abastecimento da indústria siderúrgica.

Desse montante, um dos municípios que se destacam é o de Curimatá, localizado no sul do Estado; de acordo com o IBGE (2012a), apenas no ano de 2011, o município foi responsável pela produção de 2.324 toneladas de carvão vegetal, o que gerou uma renda de 930mil reais para o município. Diante do exposto, este trabalho teve como objetivo geral diagnosticar e quantificar os impactos socioeconômicos gerados pela implantação do empreendimento ligado à atividade carvoeira para a população do município de Curimatá-PI, bem como avaliar a situação atual dos funcionários com vínculo empregatício nas carvoarias.

\section{MATERIAL E MÉTODOS}

\subsection{Descrição da área de estudo}

O município de Curimatá situa-se a $775 \mathrm{~km}$ da capital, Teresina, e localiza-se a uma latitude $10^{\circ} 02^{\prime}$ $11^{\prime \prime}$ sul e longitude $44^{\circ} 18^{\prime} 22^{\prime \prime}$ oeste, estando a uma altitude de 328 metros; possui uma área de 2.378,9 $\mathrm{km}^{2}$, com uma população de 10.761 habitantes. É composta pelos biomas do Cerrado e da Caatinga (Rodrigues, 2007). O mapa do município pode ser visualizado na Figura 1.

Primeiramente, procedeu-se à coleta de dados em campo, a qual ocorreu em duas fases: entrevistas em profundidade e aplicação de formulários. A primeira fase foi realizada com entrevistas aplicadas aos funcionários das carvoarias ou a pessoas diretamente envolvidas nessa atividade, com um total de 47 entrevistas realizadas.

$\mathrm{Na}$ segunda fase, foram elaborados e aplicados formulários aos proprietários das três carvoarias existentes, bem como à população residente no município, com um total de 240 entrevistados. Vale ressaltar que, nos questionários, preservou-se a identificação dos entrevistados. Os formulários buscam identificar a carvoaria e o seu respectivo proprietário, bem como os aspectos legais, e a importância da atividade carvoeira no município, as demandas tecnológicas, os principais mercados e as perspectivas de novos investimentos nessa atividade, como alternativa de geração de renda e emprego. Também se verificou a percepção dos moradores do município em relação aos benefícios socioeconômicos produzidos pelas carvoarias.

\subsection{Amostragem}

$\mathrm{Na}$ determinação do tamanho da amostra, ou seja, do número de pessoas entrevistadas, utilizouse a diretriz adaptada por Little (1997), demonstrada 


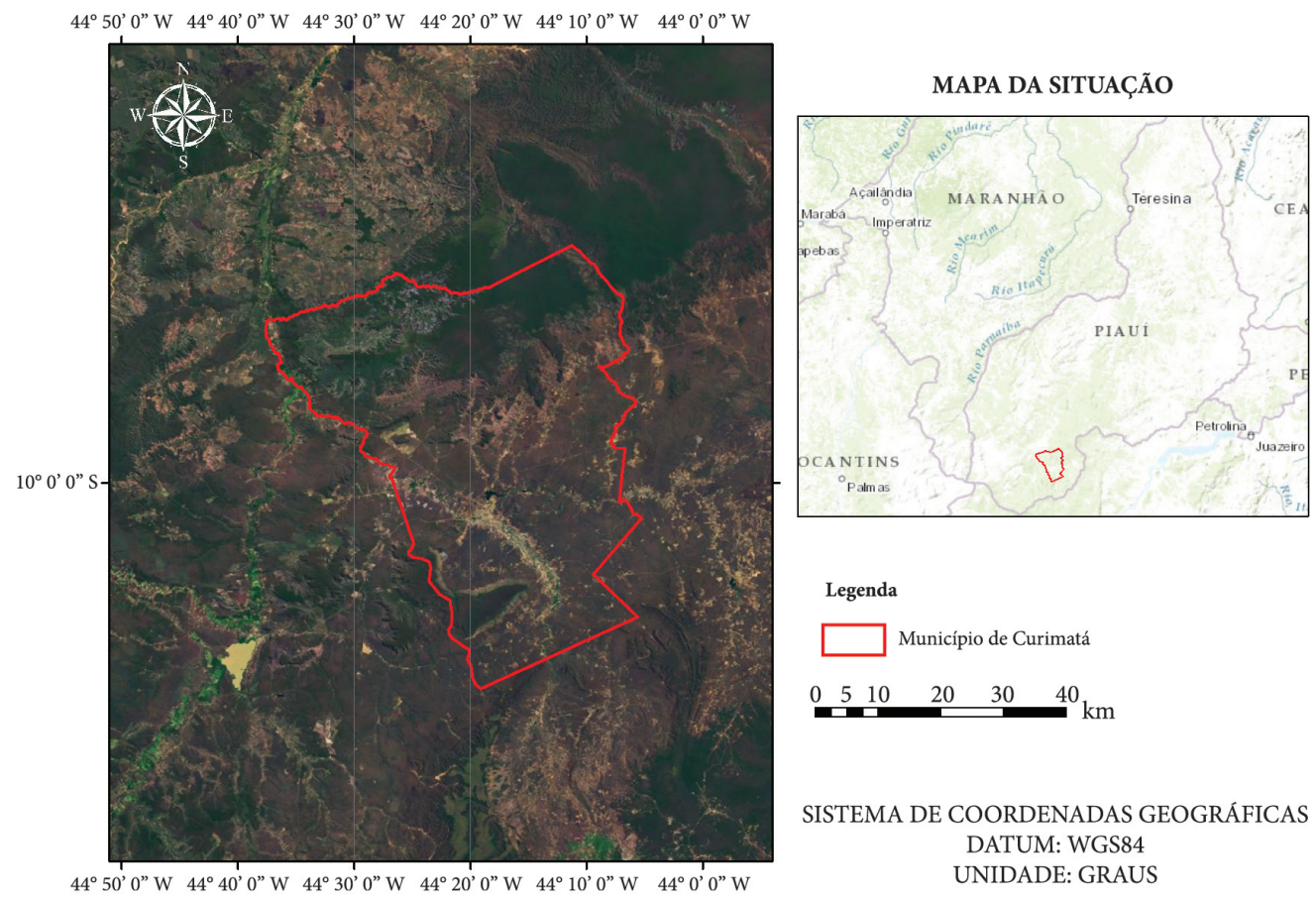

Figura 1. Mapa com a localização do município de Curimatá-PI. Imagem ao fundo fonte: GoogleEarth ${ }^{\text {. }}$

Figure 1. Map with the location of the municipality of Curimatá-PI, Picture to the background source: GoogleEarth .

na Tabela 1. A definição do número de indivíduos entrevistados foi baseada no tamanho da população, ou seja, seguindo o critério A (mais rigoroso). Portanto, foi necessária uma amostra de 2 a $3 \%$ do total, para amostragens acima de mil indivíduos, como é o caso do município em estudo.

\subsection{Processamento dos dados}

Os dados coletados durante os dois meses de pesquisa em campo foram tabulados em planilha Excel $^{\circledR}$, pós-processados em valores percentuais de forma a facilitar a análise, procedimento que se assemelha ao realizado por Silva et al. (2009). Os formulários foram aplicados aos funcionários das carvoarias, à população e aos responsáveis administrativos do empreendimento carvoeiro.

\section{RESULTADOS E DISCUSSÃO}

\subsection{Perfil dos funcionários (colaboradores) das carvoarias}

O primeiro resultado refere-se ao fato de que 93\% dos funcionários entrevistados são do sexo
Tabela 1. Diretriz para seleção do tamanho da amostra (Padrão Militar 105D).

Table 1. Guidelines for selection of sample size (Military Standard 105D).

\begin{tabular}{|cccc|} 
Tamanho da População & \multicolumn{4}{c|}{$\begin{array}{c}\text { Tamanho Mínimo para a } \\
\text { (habitantes) }\end{array}$} & \begin{tabular}{c} 
Amostra Sugerido (\%) \\
\cline { 2 - 4 }
\end{tabular} & $\mathbf{A}\left(^{*}\right)$ & $\mathbf{B}\left(^{*}\right)$ & $\mathbf{C}\left(^{*}\right)$ \\
\hline $2-10$ & 100 & 100 & 30 \\
$11-25$ & 100 & 40 & 20 \\
\hline $26-50$ & 50 & 20 & 15 \\
$51-100$ & 25 & 10 & 10 \\
\hline $101-250$ & 15 & 7 & 5 \\
\hline $251-500$ & 10 & 5 & 3 \\
\hline $501-1000$ & 5 & 3 & 2 \\
\hline Acima de 1000 & $2-3$ & 2 & $1-2$ \\
\hline
\end{tabular}

${ }^{*}$ ) A - mais rigoroso; B - mediamente rigoroso; C - menos rigoroso. Fonte: Adaptada por Little (1997).

masculino e apenas $7 \%$ do sexo feminino. Resultado semelhante foi obtido nos trabalhos de Souza et al. (2010) que, realizando um estudo sobre os sintomas respiratórios em trabalhadores de carvoarias nos municípios de Lindolfo Collor, Ivoti e Presidente Lucena, no Rio Grande do Sul, obtiveram resultados que apontavam 75\% dos entrevistados homens e $25 \%$, mulheres. 
Estes dados refletem a frequência com que a classe masculina torna-se mais adaptável ao trabalho em carvoarias. Este resultado se deve principalmente ao tipo de forno utilizado na região, feito com tijolos de barro, denominado 'Rabo quente'; segundo Sampaio (2008), quando bem operados, estes fornos são tão eficientes quanto os grandes fornos retangulares parcialmente mecanizados. Entretanto, o autor ressalta que esse tipo de processo não aproveita os voláteis da madeira e exige ainda a força física do homem para o enchimento e a descarga dos fornos de carbonização, o que explica a grande necessidade de mão de obra do sexo masculino em detrimento do sexo feminino.

Outro fator poderia ser as condições insalubres às quais, muitas vezes, os trabalhadores são submetidos durante o processo de carbonização. Um exemplo pode ser dado pelos estudos de Orozco-Levi et al. (2006), cujos autores, ao realizarem uma pesquisa no Hospital Del Mar, em Barcelona, Espanha, relatam que, das 60 mulheres internadas com problemas respiratórios, 92\% delas haviam sido expostas à fumaça de lenha ou de carvão. Este, possivelmente, constitui um dos motivos da utilização de obra masculina em detrimento da feminina.

As funções exercidas pelos trabalhadores dentro do sistema de produção das carvoarias podem ser visualizadas na Figura 2. Os dados demonstram que $37 \%$ dos entrevistados participavam da função de Forneiro, ou seja, estavam expostos diretamente à fumaça dos fornos do tipo 'Rabo quente'. Em seguida, vêm as funções de Batedor de tora, referente aos funcionários que dividem a madeira para os fornos, com 19\%, e Operador de motosserra, responsável pelo abate das árvores em campo, com 19\%.

As outras funções dos trabalhadores foram tratorista (11\%), ajudante geral (7\%) e cozinheiro (7\%). Vale ressaltar que as carvoarias analisadas não tinham todas as funções bem definidas; segundo dados de SITIEMC-MS (2010), em carvoarias, existem as funções de: ajudante geral; auxiliar de escritório ou administrativo; barrelador; carbonizador; carregador de toras; carvoejador; empilhador; gerente administrativo; gerente operacional; motorista; motorista de carreta; operador de máquina; carregadeira; operador de máquina de esteira; operador de motosserra; operador de trator de pneu e técnico de segurança no trabalho. A falta de preenchimento das funções dentro do processo acaba acarretando o excesso de incumbências para alguns.

Conforme visto, a maior quantidade de mão de obra necessária para o desenvolvimento do processo de carbonização é a de forneiro, o que ocorre devido ao tipo de forno que estas empresas utilizam ('Rabo quente'). Estes tipos de fornos, embora sejam mais simples e de baixo custo, segundo CETEC (2005), compreendem processos de carregamento - colocação de lenha no interior do forno - e, em seguida, procede-se ao fechamento da porta e ao acendimento. Este acendimento é feito colocando-se fogo nas aberturas localizadas na parte inferior da porta.

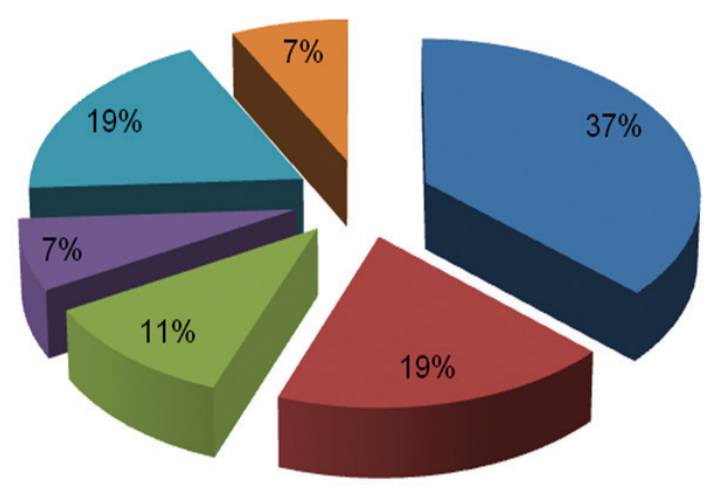

\author{
- Forneiro \\ - Operador de motosserra \\ - Tratorista \\ - Cozinheiro \\ - batedor de tota \\ - Ajudante geral
}

Figura 2. Relação em porcentagem das funções exercidas pelos funcionários das carvoarias localizadas no município de Curimatá-PI.

Figure 2. Relative percentage of the duties performed by employees of charcoal in the municipality of Curimatá-PI. 


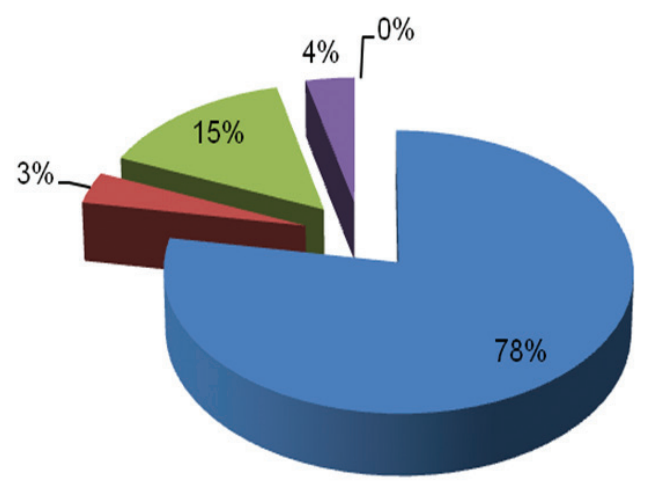

\section{- Ensino fundamental incompleto}

- Ensino fundamental completo

- Ensino médio completo

Ensino médio incompleto

-Ensino superior

Figura 3. Relação em porcentagem do grau de escolaridade dos colaboradores das carvoarias localizadas no município de Curimatá-PI.

Figure 3. Relative percentage of the level of education of employees of charcoal in the municipality of Curimatá-PI.

No início da combustão, a fumaça sai pelo próprio buraco do acendimento e é de coloração esbranquiçada; quando o forneiro percebe que a fumaça tornou-se escura, é sinal que a combustão está acontecendo. Depois do fechamento da porta, a fumaça começa a sair pelas 'baianas' e o forneiro espera até a fumaça atingir a cor azulada. Então, acontece o fechamento das 'baianas', o que ocorre em momentos diferentes. Após o resfriamento, procedese ao descarregamento do forno (CETEC, 2005).

Como pode ser visto na Figura 2, o maior número de empregos gerados corresponde à função de Forneiro; este resultado acontece devido ao tipo de forno utilizado ('Rabo quente'), tendo em vista que este método de carbonização exige grande trabalhabilidade manual.

Outro item abordado no questionário pode ser visto na Figura 3, que trata do grau de escolaridade dos funcionários. Os dados expressam que 78\% dos entrevistados possuem Ensino Fundamental incompleto; 3\% completaram o Ensino Fundamental; 15\%, o Ensino Médio, e 4\% interromperam o Ensino Médio em algum momento.

Constata-se que $78 \%$ dos funcionários possuem o Ensino Fundamental incompleto. Estes dados contribuem para justificar os valores relativos aos salários. Porém, o modelo justificador da produção carvoeira - que se pauta em melhorar economicamente a região onde é instalado - tornase um modelo ilusório, tendo em vista que, nas duas carvoarias em atividade, havia apenas 27 funcionários, dos quais 96\% recebiam um salário mínimo e $4 \%$ entre um e dois salários mínimos.

Nos trabalhos de Bethonico (2009), estudando as implicações decorrentes da produção de carvão vegetal no município de Montenuza, localizado no Estado de Minas Gerais, indica-se que, embora a justificativa para tais projetos seja de cunho econômico, a população local, que deveria ser a beneficiada com tais serviços, não se beneficiara. $\mathrm{O}$ autor comenta que os empregos gerados, além de concentrarem-se no período da implantação do projeto, pouco utilizou mão de obra local, uma vez que necessitava de certa especialização, não existente entre os moradores. Assim, estes projetos carvoeiros não geraram a dinâmica econômica pretendida, uma vez que não houve florescimento do comércio local, nem mesmo a criação de um setor terciário, que fornecesse sustentação ao ciclo econômico.

Segundo Monteiro (2006), as dinâmicas estabelecidas para produção carvoeira possibilitam a utilização, em grande escala, da mata primária, viabilizando um baixo custo na produção do carvão vegetal, fundamental para estes empreendimentos. Isto geralmente ocorre em detrimento do custo de mão de obra, gerando, assim, poucos empregos e baixa circulação de capital na região do empreendimento.

Outro parâmetro abordado foi o número de membros que estes funcionários têm em sua família; os dados demonstram que $41 \%$ possuem três pessoas na família; 37\%, quatro pessoas; $18 \%$, duas pessoas, e com $4 \%$, os que tinham até cinco membros em sua família. Tendo em vista que 


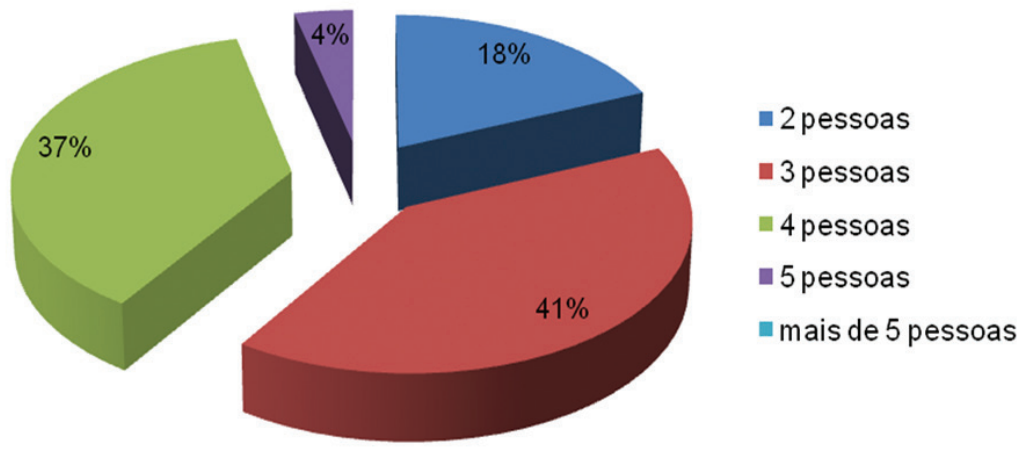

Figura 4. Relação do número de membros da família dos colaboradores das carvoarias localizadas no município de Curimatá-PI.

Figure 4. Ratio of the number of family members of employees of charcoal in the municipality of Curimatá-PI.

estes trabalhadores recebem um salário mínimo e, segundo a Consolidação das Leis do Trabalho (CLT), ou popularmente conhecida como a lei dos trabalhadores, no seu artigo 81, diz-se que este valor deve ser suficiente para abater as despesas com comida, casa, roupas, produtos de higiene e transporte. Os trabalhadores que possuem três, quatro e cinco membros na família podem ter dificuldades de obter todos os recursos necessários ao bem-estar social dos mesmos. Estes resultados podem ser vistos na Figura 4.

Outro ponto abordado foi com relação à satisfação dos funcionários, em que 100\% afirmam que houve uma melhoria na qualidade de vida com a chegada destes empreendimentos. Dentre os entrevistados, $88,91 \%$ não têm a pretensão de mudar de ramo, enquanto $11,11 \%$ aguardam oportunidade para abandonarem este segmento.

\subsection{Percepção da população em relação às carvoarias instaladas no município}

Com relação à percepção da população curimataense, os dados demonstram que 45,57\% das pessoas entrevistadas são do sexo masculino e $54,43 \%$ representam o sexo feminino, demonstrando imparcialidade de gênero.

Outro item abordado refere-se aos benefícios que as carvoarias haviam trazido ao município, em que $77,85 \%$ afirmam que a atividade carvoeira não trouxe qualquer benefício ao município e apenas $22,15 \%$ alegam que, a partir da instalação e da operação deste empreendimento no município, houve algum tipo de benefício econômico.

Tal dado entra em contradição com os dados fornecidos pelos funcionários, uma vez que 100\% afirmaram que foram beneficiados com a instalação das carvoarias, como visto no item 3.1. Porém, o número de funcionários é inferior a 50 indivíduos, enquanto a população do município chega a 10.761 habitantes.

Estes dados são confirmados quando a população responde outra pergunta: 'Você foi beneficiado, financeiramente, por esta atividade?'. O resultado demonstra que $89 \%$ dos indivíduos responderam que não foram beneficiados por esta atividade e somente $11 \%$ explanaram que obtiveram algum benefício financeiro promovido pelo empreendimento. Vale ressaltar que $82 \%$ da população afirmou ter uma visão negativa de empreendimentos carvoeiros.

\subsection{Visão geral dos responsáveis pelas carvoarias sobre este empreendimento}

Nesta etapa, foram realizadas novas entrevistas com os responsáveis pela gerência de três carvoarias (A, B e C), sendo que a carvoaria C desativou o empreendimento em novembro de 2012. Os responsáveis por estes projetos defendem a atividade carvoeira no município, argumentando que a geração de emprego e a movimentação na economia foram, significativamente, influenciadas a partir da instalação desta atividade. 
A empresa (A) tem por objetivo o reflorestamento com espécies exóticas e nativas, tais quais Eucalipto ssp, Acácia (Acacia Mollissima), Pau d’arco (Tabebuia Caraiba), Jatobá (Hymenaea courbari) e Mogno africano (Khaya ivorensis), tendo assim o objetivo de praticar a produção apícola e o uso de outras espécies para produção madeireira. $\mathrm{O}$ gerente, responsável pela carvoaria $\mathrm{B}$, relatou que a atividade carvoeira é transitória, pois há perspectiva da implantação de lavouras agrícolas, como milho e soja, e, posteriormente, implantação de sistemas agroflorestais que agreguem a criação de animais.

O responsável pela gerência da carvoaria $C$ alegou que o principal motivo para a interrupção da atividade deveu-se à polêmica ambiental gerada em torno da existência ou não do Bioma Mata Atlântica no Estado do Piauí. Este fato tem gerado muitas discussões na região; entretanto, pesquisas realizadas por Castro et al. (2009), em que os autores realizaram levantamento fitossociológico em Curimatá e outros municípios circunvizinhos, e compararam com outros 12 levantamentos realizados em vários tipos de vegetação de Mata Atlântica e mais seis levantamentos realizados em Floresta Estacional Semidecidual do bioma da Caatinga, geraram resultados que permitiram aos autores classificar a vegetação da região como Floresta Estacional Semidecidual de Transição, apresentando assim mais semelhança com a Caatinga do sedimentar e principalmente com o Carrasco, não classificando assim a área como Mata Atlântica do Nordeste. O autor complementa seu trabalho afirmando que isto não isenta a conservação da área, em razão de seu caráter insubstituível.

De acordo com Uhlig et al. (2008), os recursos provenientes de florestas nativas estão cada vez mais escassos, sobretudo nas regiões próximas aos centros produtores de ferro-gusa, considerando-se que grande parte do desenvolvimento da agricultura já ocorreu nestas áreas. Como resultado, as distâncias entre as fontes de carvão e as siderúrgicas estão aumentando.

Mesmo o produto final não permanecendo no município, os responsáveis relatam que todos os gastos com mão de obra, manutenção de maquinaria, locação de imóveis, fretes e impostos favorecem a movimentação econômica local.

\section{CONCLUSÃO}

A pesquisa demonstra que, apesar da geração de empregos diretos e indiretos, e de renda aos habitantes do município, há divergência entre as opiniões da população e dos funcionários das carvoarias: enquanto os proprietários e funcionários defendem a atividade na região, a maioria da população reage de forma contrária ao empreendimento.

\section{STATUS DA SUBMISSÃO}

Recebido: 17 abr., 2013

Aceito: 29 mar., 2014

Publicado: 30 jun., 2014

\section{AUTOR(ES) PARA CORRESPONDÊNCIA}

\section{Sidney Araujo Cordeiro}

Departamento de Engenharia Florestal, Universidade Federal dos Vales do Jequitinhonha e Mucuri - UFVJM, CEP 39100-000, MG, Brasil e-mail: sidney.cordeiro@ufvjm.edu.br

\section{REFERÊNCIAS}

Associação Brasileira de Produtores de Florestas Plantadas - ABRAF. Anuário estatístico da ABRAF 2008: ano base 2007. Brasília; 2008.

Bethonico MB. Implicações da produção de carvão vegetal no município de Montenuza/MG: percepção da população local. Geografia: Ensino \& Pesquisa 2009; 13(1): 10-21.

Castro AAJF, Castro ASF, Farias RRSF, Sousa SR, Castro NMCF, Silva CGB, et al. Diversidades de espécies e ecossistemas da vegetação remanescente da Serra Vermelha: área de chapada, municípios de Curimatá, Redenção do Gurguéia e Morro Cabeça no Tempo, sudeste do Piauí. Publicações Avulsas em Conservação de Ecossistemas 2009; 23: 1-72.

Fundação Centro Tecnológico de Minas Gerais - CETEC. Produção e utilização de carvão vegetal. Belo Horizonte; 2005. 393 p. Séries Técnicas.

Homma AKO, Alves RNB, Menezes AJ, Matos GB. Guseiras na Amazônia: perigo para a floresta. Ciência Hoje 2006; 39(233): 56-59.

Instituto Brasileiro de Geografia e Estatística - IBGE. Extração vegetal e silvicultura 2011. Rio de Janeiro; 2012a. [cited 2013 June 24]. Available from: 
http://www.ibge.gov.br/cidadesat/xtras/temas. php? $\operatorname{codmun}=220320$ \&idtema $=102$.

Instituto Brasileiro de Geografia e Estatística - IBGE. Produção da extração vegetal e da silvicultura 2011. Rio de Janeiro; 2012b. [cited 2013 June 24]. Available from: http://www.ibge.gov.br/home/estatistica/economia/ pevs/2011/default.shtm.

Little AD. Auditoria de meio ambiente, saúde ocupacional e segurança industrial: fundamentos, habilidades e técnicas. São Paulo: Arthur D. Little; 1997. 270 p. Apostila.

Monteiro MA. Em busca de carvão vegetal barato: o deslocamento de siderúrgicas para Amazônia. Novos Cadernos NAEA 2006; 9(2): 55-97.

Moura APM, Campos JE, Magalhães SR. Melhoria da qualidade de serviço na produção de carvão no setor de carbonização: um estudo de caso. Revista da Universidade Vale do Rio Verde 2010; 8(1): 19-26. http:// dx.doi.org/10.5892/ruvrv.2010.81.1926

Orozco-Levi M, Garcia-Aymerich J, Villar J, Ramírez SA, Antó JM, Gea J. Wood smoke exposure and risk of chronic obstructive pulmonary disease. European Respiratory Journal 2006; 27(3): 542-546. PMid:16507854. http://dx.doi.org/10.1183/09031936.0 6.00052705

Piauí. Secretaria do Meio Ambiente e Recursos Hídricos do Piauí - SEMAR. Fiscalização em carvoarias. Piauí; 2011. [cited 2011 July 20]. Available from: http://www. semar.pi.gov.br

Rodrigues JLP. Geografia e história do Piauí: estudos regionais. 4. ed. Teresina: Halley; 2007. p. 329.
Sampaio RS. Conversão da biomassa em carvão vegetal situação atual com tendências 2025: estudo prospectivo do setor siderúrgico. Belo Horizonte: Centro de Gestão e Estudos Estratégicos; 2008. [cited 2013 June 24]. Available from: http://www.ciflorestas.com.br/ arquivos/doc_conversao_tecnica_1531.pdf.

Silva FL, Griffith JJ, Jacovine LAG, Valadares JH, Fernandes MAS, Silva ECG. Estudo da relação de confiança em programa de fomento florestal de indústria de celulose na visão dos produtores rurais. Revista Árvore 2009; 33(4): 723-732. http://dx.doi. org/10.1590/S0100-67622009000400015

Sindicato Intermunicipal dos Trabalhadores em Indústrias Extrativas, Mineração e Carvão Vegetal em Geral de Mato Grosso do Sul - SITIEMC-MS. Mato Grosso do Sul; 2010. [cited 2013 Jan 24]. Available from: http://sitiemcms.blogspot.com.br/2010/03/primeiroacordo-coletivo-das-carvoarias.html.

Souza RM, Andrade FM, Dewes Moura AB, Zimermann Teixeira PJ Sintomas respiratórios em trabalhadores de carvoarias nos municípios de Lindolfo Collor, Ivoti e Presidente Lucena, RS. Jornal Brasileiro de Pneumologia 2010; 36(2): 210-217. PMid:20485942.

Uhlig A, Goldemberg J, Coelho ST. O uso de carvão vegetal na indústria siderúrgica brasileira e o impacto sobre as mudanças climáticas. São Paulo - SP. Revista Brasileira de Energia 2008; 14(2): 67-85.

Vital MH, Pinto MA. Condições para a sustentabilidade da produção de carvão vegetal para fabricação de ferrogusa no Brasil. Rio de Janeiro: BNDES; 2009. BNDES Setorial 30. 